\title{
The Phonological Word and Stress Shift in Northern Kurmanji Kurdish
}

\author{
Aveen Mohammed Hasan, PhD \\ University of Zakho, Kurdistan-Region, Iraq
}

doi: 10.19044/esj.2016.v12n26p370 URL:http://dx.doi.org/10.19044/esj.2016.v12n26p370

\begin{abstract}
It is generally believed that stress in Kurdish is word-final. However, closer examination reveals several kinds of exceptions. This study proposes a unified analysis of regular and irregular stress patterns in Northern Kurmanji. It analyses the stress-assignment rule on the basis of a framework of prosodic phonology that divides the representation of speech into hierarchically organised units. It proposes the phonological word as the domain of stress rule and a number of other phonological processes such as glide insertion, resyllabification, vowel deletion, vowel shortening. Additionally, it proposes the cyclic analysis as the method of the rule application. Cases of stress rule violation are considered as instances of stress-shift which are conditioned by different phonological and syntactical factors or they can be accounted for by using recursive structure and phrase stress rule.
\end{abstract}

Keywords: Phonological word, stress shift, cyclicity, recursivity, phrase stress rule

\section{Introduction}

Kurdish is known to have a simple stress rule that places stress on the word final syllable irrespective of its length or syllable weight (Bedir Khan and Lescot, 1970; Fattah, 1980; Qadir, 1983; Ahmed, 1986; Shokri, 2002). The rule is applied to simple (1a), complex (1b) and compound words (1c). Throughout the paper, the examples are written using the Latin Kurmanji writing system ${ }^{69}$, their transcription is given using IPA (revised version 93) in slashes and their meanings in English are given in rounded brackets.

${ }^{69}$ Kurdish is written in different writing systems, namely modified Arabic, Latin Kurmanji and Cyrillic. Even in the symbols within these systems differ between the scholars and they do not contain symbols for a lot of sounds which are also identified in Kurdish. This study adopts the Latin Kurmanji writing system (Kurdish Academy of Language, 1992) because it is very close to the English writing system, it is very close to the IPA phonetic transcription system used and because for Kurmanji dialect the Latin is more of a norm. Some letters which give different sound symbols include [a] for $/ \mathrm{a}: /$, [c] for $/ \mathrm{d} z /$, [ç] for $/ \mathfrak{y} /$, [e] for $/ \mathrm{a} /$, [ê] for $/ \mathrm{e}$ : 
$1-$

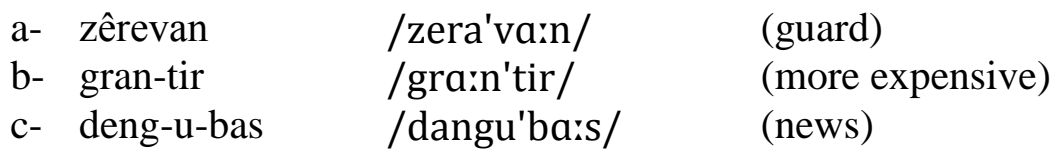

In addition to this regular stress pattern, Kurdish also has a number of instances of non-final stress (Fattah, 1980). Firstly, non-final stress arises as the result of the attachment of certain suffixes. Two types of suffixes are recognised: stress-bearing and non-stress bearing suffixes. Stress-bearing suffixes include (Qadir, 1983 and Bedir Khan and Lescot, 1970): suffixes forming the plurals $\langle a n\rangle$ and $\langle h a\rangle$, the comparative $\langle t i r\rangle$, the superlative $\langle$ tirîn $\rangle$ (examples in 2), $\langle e m\rangle$ and $\langle e m i n\rangle$ which are used to form ordinal numbers (3), the suffix clitics $\langle i m, \hat{\imath}, \hat{\imath}$, $\hat{\imath}$, in $\rangle$ (4), the suffix $\langle-\hat{1}\rangle$ which is used to form abstract nouns and <-çî> used to form nouns (5):
2- jin /'zin/ (woman) jin-an /3i'na:n/ (women) hezar /ha'za:r/ (thousand) hezare-ha /haza:ra'ha:/ (thousands) $\begin{array}{lll}\text { gran /'gra:n/ } & \begin{array}{l}\text { gran-tir /grain'tir/ } \\ \text { (more expensive) }\end{array} & \begin{array}{l}\text { gran-tir-în /gra:nti'ri:n/ } \\ \text { (most expensive) }\end{array}\end{array}$
3- yek /'jak/ yek-em /ja'kam/ yek-emîn /jaka'minn/ (one) (the first)
4- dê-koj-im/de:ko'zim/ dê-koj-în /de:ko'zi:n/ (we will kill) FUT-kill $1{ }^{\text {st }}$ SING (I will kill)
5- mêran-î /merra:'ni:/ qehwe-çî /qahwa'tfi:/ FUT-kill- $1^{\text {st } P L}$ (courage) (person who serves coffee) Non-stress bearing suffixes include (according to Fattah, 1980, Qadir, 1983, Ahmed, 1986 \& Thackston, 2006): gender markers: $\langle\hat{\imath}\rangle$ for masculine and $\langle\hat{e}\rangle$ for feminine, indefinite <ek or yek>, possessive linking $\langle\hat{e}\rangle$ for masculine and $\langle a\rangle$ for feminine and $\langle\hat{e} n\rangle$ for plural, present copulas $\langle i m, \hat{l}$, $e$, in $\rangle$, personal pronoun clitics $\langle i m, \hat{\imath}, i n\rangle$ and postposition suffix $\langle d a\rangle$. These suffixes do not bear stress, and thus result in word non-final stress. In 6 , we provide some examples in which the relevant suffixes are underlined.
6- a- mamosta-yek teacher-SING-INDEF
/ma:mos'ta:jak/
(a teacher)
b- li Kurdistan-ê-da
/ li kurdista:'neda:/
(in Kurdistan)
c- xand-im
/'xa:ndim/
(I read)
read-PAST- $1^{\text {st }}$ SING

Secondly, non-final stress results from the attachment of certain stress-bearing prefixes. These include: the negative prefixes $\langle n a-\rangle$ used with present tense only (7a), <ne->used with all other tenses (7b) and the imperative prefix $<b i$ $>(8)$.
7- a- na-xo-m
/'na:xom/ (I don't eat.)

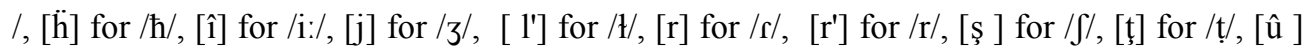
for $/ \mathrm{u}: /,[\ddot{\mathrm{x}}]$ for $/ \mathrm{y} /$, , $[\mathrm{y}]$ for $/ \mathrm{j} /$ and $\left[\mathrm{E}^{\prime} \mathrm{e}^{\prime}\right]$ for $/ \mathrm{S} /$. 


\section{NEG-eat-PRE- ${ }^{\text {st }}$ SING \\ b- ne-hat \\ NEG-come-PAST-3 ${ }^{\text {rd }}$ \\ SING \\ 8- bi-nvîs-e \\ IMP-write-SING \\ /'nahait/ (He didn't come.) \\ /'binvissa/ (write.)}

Thirdly, non-final stress is due to some syntactic factors. For example, in the imperative case in compound verbs and in vocatives stress is placed on the word initial syllable (Ahmed, 1986), as in 9 and 10 respectively.
9- rawest-e IMP- stand up-SING
10- xalet
/'ra:wasta/
(stand up.)
/'xa:lat/
(aunt)

The common claim among earlier works on Kurdish stress is that stress is assigned to a word as a whole after all the morphological operations have taken place. However, this approach creates a large number of exceptions as shown above. Therefore, we argue that stress is assigned cyclically to the ultimate syllable following every morphological word-formation process and we propose the Phonological Word (henceforth PW) as the domain of the rule in one of the most widely spoken dialects of Kurdish, namely Northern Kurmanji (henceforth NK). Additionally, we indicate that different phonological, morphological and syntactic factors interact with the stress in NK and lead to rule application failure. We will propose the stress shift rule to account for the instances of stress application violation and show the way it is governed by different factors: phonological and syntactic. Other cases of failure are accounted for by using recursive structure and phrase stress rule.

The study is based on data collected from recorded read speech and interviews with the native speakers of NK which were recorded for a previous study on intonation. The speech was recorded at a sampling frequency of $44,100 \mathrm{~Hz}$ and analysed using PRAAT.

The following section provides an introduction to the PW in NK and defines the various segmental and prosodic rules that occur within its domain. After that, stress in NK is analysed and a cyclic analysis is proposed as the method of its application. Finally, cases of stress rule violation are discussed which are considered instances of stress-shift conditioned by different factors. The phonologically conditioned stress shift is discussed, then recursivity and phrase stress rule and finally syntactically-conditioned stress shift.

\section{The phonological word in Northern Kurmanji}

The phonological word is a constituent of the prosodic hierarchy that is larger than the syllable or foot but smaller than the phonological phrase. It is also referred to as a prosodic word and represents the interaction between the phonological and morphological components of the grammar. It is defined 
by Nespor and Vogel (2007: 109) as 'the lowest constituent of the prosodic hierarchy which is constructed on the basis of the mapping rules that make substantial use of non-phonological notions'. These rules regroup the terminal elements of morphological word structure in such a way that the resulting constituents do not necessarily correspond to any morphological units.

Numerous studies (e.g. Nespor \& Vogel, 2007; Hannahs, 1995; Kabak \& Vogel, 2001, Booij, 1996, to mention but a few) have provided evidence for the need of the phonological word as a prosodic constituent since it forms the domain for various phonological generalisations. In this study, it will be identified as the phonological word which is abbreviated as PW.

It is repeatedly emphasised in the literature that the PW is nonisomorphic with the grammatical word (the terminal element of the syntactic tree). In some languages such as Turkish, Hungarian, French and Italian, it can be smaller than the grammatical word, i.e. a single grammatical word may consist of two or more PWs. For example, each part of the compound or both the prefix and the following stem form separate PWs (Nespor and Vogel, 2007, for French see Hannahs, 1995 and for Turkish see also Kabak \& Vogel, 2001). In other languages such as Latin and Greek, its domain can be equal to the grammatical word in that a single grammatical word constitutes a single PW (Nespor and Vogel, 2007). In some other attested languages, for example Dutch and English, the PW has been argued to consist of two grammatical words, for example, a sequence of lexical word and a clitic form a PW (see Booij, 1996 for Dutch and Selkirk, 1995 for English).

None of the previous studies on Kurdish stress (such as Fattah, 1980; Qadir, 1983 and Ahmed, 1986, Mosa, 2009) however have considered the PW before. After examining some data, the study reveals that there are some phonological processes that seem not to refer to the word level but to more complex domains. On the basis of these analyses we establish the following definition of the PW in NK.

11- The PW in NK is a prosodic constituent with the following structure:

a- prefixes

b- (prefixes) + stem + (suffixes)

c- compounds

d- lexical word + clitic

The brackets indicate optional elements. According to the definition, prefixes, simple, complex and compound words are considered single PWs in NK. (d) shows that it may consist of two grammatical words: a sequence of a lexical word+a clitic. Accordingly, the NK's PW behaves similar to Dutch and English PWs, i.e. it is larger than a grammatical word. To support this definition, some data have been examined. 


\section{Phonological rule application in the $\mathrm{PW}$ domain}

This study discusses some phonological processes that define the PW domain, namely we are going to look at glide insertion, resyllabification, /i/ vowel-deletion, vowel shortening, stress-assignment and stress-shift.

\section{Glide insertion}

Glide insertion (henceforth GI) is analysed in the literature on Kurdish morphology as that by adding a vowel-initial suffix to a vowel-final stem, an [y] (=/j/ IPA) is inserted (Fattah, 1980; Thackston, 2006; Yasin, 2006). For example, the indefinite suffix has two forms: $\langle e k\rangle$ is added to consonant-final words and $\langle y e k\rangle$ is added to vowel-final words, as in 12a and b:

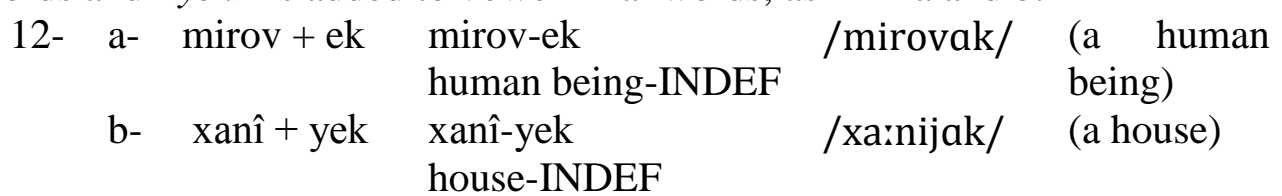

GI is found in a number of languages such as Polish (Rubach, 1984), Dutch (Booij, 1996), Japanese (Kawahara, 2002), Russian (Molczanow, 2008), Persian (Dehghan, 2012) to mention but a few. In all theses languages, GI is the most frequent phonological process whose context is well-defined: [j] is inserted in the context of preceding or following high vowels and [w] in the contextof preceding or following non-high vowel and it has the functions of avoiding vowel hiatus and militating against onsetless syllables.

As in these languages, in NK GI is applied to avoid word-medial vowel clusters at root-suffix boundaries (Hasan and Rasheed, 2016). It is a phonological process applied when a vowel-initial suffix is added to a vowelfinal stem, $/ \mathrm{j} /$ is inserted and according to onset requirements it acts as the onset of the vowel-initial suffix.

Hasan and Rasheed (2016) provide an analysis of GI in word-medial vowel clusters in Kurdish and analyse the effects of dialect and segmental context on GI. Their study is based on a set of words consisting of a stem+suffix with different vowel sequences at their boundaries which are produced by four native speakers from four Kurdish speaking areas, namely, Duhok, Diyarbakir, Qamishlo and Hewler. Their results indicate that GI is not the only strategy used as word medial hiatus resolution, but it depends on the segmental context and dialect. They indicate that generally the vowel hiatus is resolved by / $\mathrm{j} /$ insertion, but vowel deletion and $/ \mathrm{w} /$ insertion is also used in some segmental contexts and dialects. Thus, they conclude that $/ \mathrm{j} /$ insertion is the default strategy to resolve word-medial vowel clusters in Kurdish, the insertion of $/ \mathrm{w} /$ or vowel deletion are other strategies which are limited to some dialects and vowel sequences.

Additionally, GI rule does not apply across word boundaries, as in:
13- a- evru arî
/avru arri:/
(Today Ari...)
(not evru yarî) 


$$
\text { b- vê avê /ver arve:/ (This water) (not vê yavê) }
$$

Thus, GI in NK is a domain span rule which is applied word-internally at stem+suffix boundaries. In Dutch (Booij, 1996), GI occurs obligatory within word+clitic combinations and it is one of the rules that provide an evidence that the combination of word+clitic is a PW. Since GI does not apply across PW boundaries, as it is shown in the examples in 13, and similar to languages, such as Dutch, in which the PW is considered as the domain of GI, we argue that the PW represents the domain of GI rule in NK and hence the structure 'stem+suffix' is a PW. Thus, we can formulate the rule as:

14- Glide insertion rule: $\emptyset \rightarrow / \mathrm{j} / /\left[\ldots \mathrm{V} \_\mathrm{V} \ldots\right]_{\mathrm{PW}}$

The rule can be interpreted as within the PW domain, /j/ is inserted between two adjacent vowels.

\section{Resyllabification}

Examination of our data revealed that when a vowel-initial suffix is added to a consonant-final stem, that consonant will syllabify as the onset of the initial syllable of the vowel-initial suffix. This process is known as resyllabification or syllabification which occurs when a stem-final consonant becomes the onset of the following vowel-initial suffix as the result of onset requirements (Hall, 2000). Some examples of word-medial syllabification are given in 15:

\begin{tabular}{|c|c|c|c|}
\hline $\operatorname{baran}+\hat{\imath}$ & ba.ra.nî & /barra:ni:/ & $\begin{array}{l}\text { Baran-MASC } \\
\text { (a proper noun) }\end{array}$ \\
\hline yek +em & ye.kem & /jakam/ & (the first) \\
\hline
\end{tabular}

It can also occur between a lexical word+a clitic, for instance, between a verb+personal pronoun clitics an in 16 a or between an adjective and present tense copulas, as in $16 \mathrm{~b}$ :
16- a- hat + im ha.tim /hartim/ come-PAST- ${ }^{\text {st }}$ SING (I came)
b- tu kurd $+\hat{\imath}$ tu kur.dî /tu kurdi:/ you-Kurdish-2 $2^{\text {nd }}$ SING (you are Kurdish)

In these examples, resyllabification takes place to prevent onsetless syllables in NK. Resyllabification can be resulted from vowel deletion process (Hasan and Rasheed, 2016). For example, when personal pronoun clitics begining with vowel /i/ are added to a vowel-final verbs, /i/ is deleted and the remaining consonant will syllabify as the coda of the open syllable of the stem, as in 17 (see Hasan and Rasheed, 2016 and /i/ vowel deleltion section below for other cases of vowel deletion).
17- çû + in çûn
/tuin/
go-PAST- $3^{\text {rd }}$ PL (they went)
bixo + in bixon
/bixon/
eat-IMP.-2 $2^{\text {rd }}$ PL (You eat.) 
Furthermore, resyllabification is blocked if a consonant-initial suffix is added to a consonant-final stem, as in:

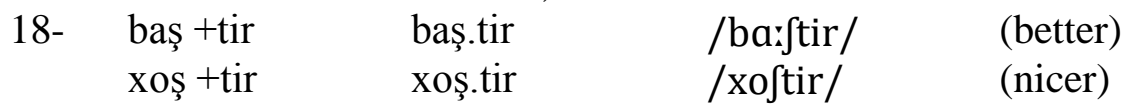

In those cases syllabification follows requirements of the sonority hierarchy.

As the GI rule, resyllabification does not occur across word boundaries but only word-internally as illustrated in 19:

19- pşik înan /pjirkinna:n/ (they brought cats) (not pşîkî.nan)

ev ahenge /av a:hanga/ (this party) (not e.va.hen.ge)

In languages like German and English (Hall, 2000), the PW is the domain of resyllabification. Hall (2000) claims that in English (e.g. 20a) and in German (e.g. 20b) resyllabification occurs only when a vowel-initial suffix is added to a consonant-final stem but the rule is blocked when a consonantinitial suffix is added (examples from Hall, 2000: 45-46).
20-
a- pimple + ous
[pımp-ləs]
rump + less
b- lieb+e
[li:-bə] (love) lieb+lich
[rımp-ləs]
[li:p-lıḉ] (dearly)

Hall also finds that this process only occurs word-internally in English and German and concluded that the PW is the domain of the rule.

Resyllabfication has also been observed by Booij (1996) in Dutch. He states that enclitics are syllabified with a preceding word. Since the PW has been suggested to be the domain of resyllabification, Booij concludes that the structure lexical word+clitic constitutes a PW in Dutch, as illustrated in 21a and $b$ (examples from Booij, 1996: 225):

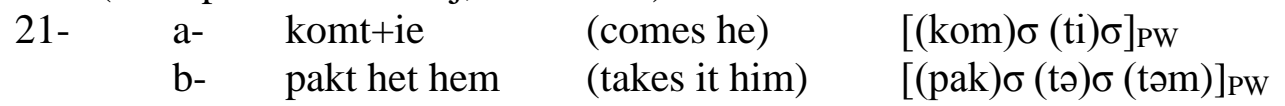

Since resyllabification does not occur across PW boundaries, as shown in 19, and similar to languages such as German, English and Dutch, we argue that the $\mathrm{PW}$ is also the domain of resyllabification in NK. It is a prosodic rule that is applied word-internally between a stem+suffix or between a lexical word +a clitic however it is blocked across word boundaries or between a consonant-initial suffix and a consonant-final stem. Accordingly, the structures 'stem+suffix' and 'lexical word+clitics' are PWs in NK because they represent the domain of resyllabification.

\section{/il vowel deletion}

Examination of our data revealed that the vowel /i/ in unstressed CV syllables is deleted in most occurrences. However, it was realised in careful slow speech of some speakers. When /i/ is elided an obligatory resyllabification occurs in that the remaining consonant syllabifies to form a cluster with the onset of the following syllable. We identify this process as /i/ vowel deletion rule as in 22:

22- /i/ vowel deletion rule: $/ \mathrm{i} / \rightarrow \emptyset /\left[\mathrm{C}_{\ldots}[\text { [ }[\text { cons }] \ldots]_{\mathrm{PW}}\right.$ 
The rule states that $/ \mathrm{i} /$ is deleted in $\mathrm{CV}$ syllables when it is followed by a consonant-initial syllable within the PW-domain. This rule is applied between a prefix+stem as in the case of the progressive prefix $\langle d i\rangle$ (23a) and in monomorphemic words (23b):

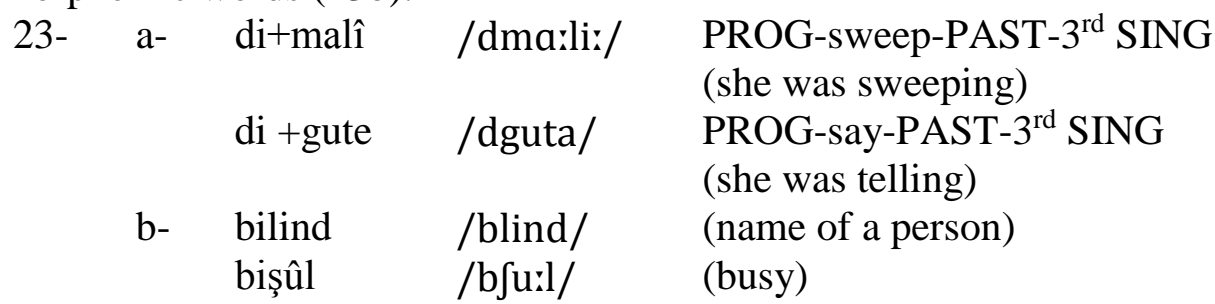

Furthermore, the rule is applied between monosyllabic prepositions which have the structure $\mathrm{Ci}$, such as $\langle j i\rangle$ (from), $\langle b i\rangle$ (by), $\langle l i\rangle$ (in) and the following word. Examples:
24-
$\mathrm{ji}+$ mal
$\mathrm{bi}+\mathrm{sev}$
/3ma:l/
(from home)
/bJav/
(at night)

In all these examples, when /i/ of the $\mathrm{Ci}$ is deleted, the remaining onset consonant is resyllabified to form an onset cluster with the following syllable. Thus, the / $\mathrm{i} /$ deletion in the sequences of prefix+stem (as in 23a) and clitic+lexical word (as in 24) induces resyllabification, thus the remaining non-syllabic consonant will syllabify into the onset of the following syllable. Because PW is the domain of resyllabification in NK as it is stated above, this suggests that the sequences prefix+stem and clitic+lexical word constitute single PWs. In this respect, monosyllabic Ci prepositions behave in the same way as Ci prefixes and form a part of the following word as one PW.

A similar process has been described for French by Harris (2011). Vowel deletion occurs to avoid vowel sequences. For example, when the masculine [le] or the feminine [la] determiners precede a vowel-initial noun, the vowel of the determiner is elided and the remaining consonant is syllabified as the onset of the following vowel-initial syllable, as in:

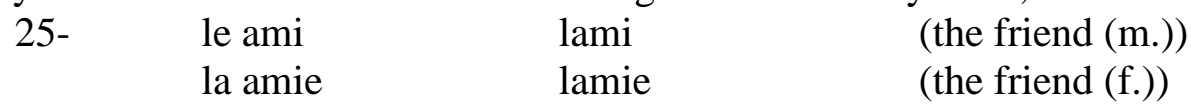

In Dutch (Booij, 1996), vowel deletion is also found within words and in host+enclitic constructions. When the vowel is elided obligatory resyllabification occurs and in the case of host+enclitic the enclitic is integrated with the preceding host in one PW, e.g. (from Booij, 1996: 226)

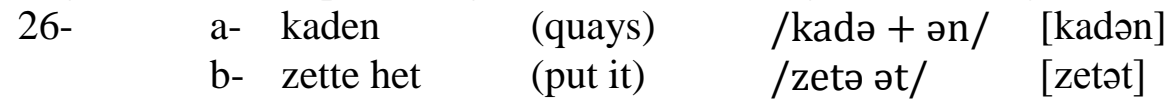

In (a) the rule is applied within the word <kaden >, while in (b) it is applied between the word <zette> and the enclitic, pronoun <het>. In Dutch, clitics with schwa cannot be dominated by higher prosodic structure such as the PW because they do not contain full vowels (Booij, 1996). So they are integrated into a single PW with an adjacent word, as in: 
27- [Jan $]_{\mathrm{N}}\left[[\text { kocht }]_{\mathrm{V}} \text { [het boek] NP }\right]_{\mathrm{VP}}$ (John bought the book) $[j a n]_{\mathrm{PW}}[(\mathrm{kox}) \sigma(\text { tet }) \sigma]_{\mathrm{PW}}[\mathrm{buk}]_{\mathrm{PW}}$

(Booij, 1996: 219)

The weak form of the determiner <het $\rangle$ depends syntactically on the following noun, but prosodically on the preceding verb with which it forms one PW. Likewise, in English, in the example <Bob's swimming > (Hall, 1999: 12 ), the weak form that consists of a single non-syllabic consonant $[\mathrm{z}]$ belongs to the same syllable and PW as the preceding word.

Similar to Dutch and English, in NK, the remaining consonant of the monosyllabic clitic belongs to the same syllable and PW as the following word. Thus, the weak forms of function words fuse together into a single prosodic unit with an adjacent word.

\section{Vowel shortening}

Thackston (2006) claimed that when a stress-bearing suffix is added to a word that ends in an open stressed syllable with a long vowel, the vowel in that syllable is shortened and destressed because stress is shifted to the suffix. Consider the following examples from Thackston (2006: 8):

$$
\begin{aligned}
& \text { 28- a- gun'dî + an gundi'yan /gundi'ja:n/ villager-PL } \\
& \text { (villagers) } \\
& \text { b- o'dê + an ode'yan /oda'ja:n/ room-PL (rooms) }
\end{aligned}
$$

In these examples, the long vowel of the stem final syllable is shortened and destressed when the stress-bearing suffix $\langle a n\rangle$ is added. Additionally, /j/ is inserted to avoid vowel clusters.

This rule is known as vowel-shortening that is applied when a stressbearing suffix is added to a stem that ends in an open stressed syllable with a long vowel nucleus. In such cases, the long vowel is reduced in length and destressed because stress is moved to the suffix. The rule is formulated as: 29- vowel shortening: $\mathrm{V}: \rightarrow\left(\begin{array}{l}\text {-stress } \\ \text { long }\end{array}\right] /[\ldots \ldots[1 \text { stress suffix }]]_{\mathrm{PW}}$

The rule indicates that the stressed syllable with a long vowel is destressed and reduced in length when a stress-bearing suffix is added within the PW domain. Actually, two processes occur here. First, the stem final stressed syllable will be destressed. Second, the length of the syllable which undergoes destressing will be reduced.

Thus, vowel-shortening occurs word-internally between a stem and a suffix. Because the sequence stem+suffix is considered a PW in NK according to the definition found in 11 and because the PW represents the domain of GI and resyllabification rules, we deduce that the PW is also the domain of the vowel-shortening rule.

A similar rule is also observed for some languages. In English, for instance, Liberman and Prince stated that in <explain-explanation> the second syllable of <explain > is destressed and reduced in length when the stress-bearing suffix 
<-ation> is added (1977: 285). In Catalan (Mascaró, 1976), word stress always falls on one of the last three syllables of the word, but is generally unpredictable beyond that. Therefore stress must be located in the underlying representation. Any stem loses its stress when followed by a stressed affix.

This makes necessary a rule which destresses a vowel before another stressed vowel. In unstressed syllables the vowels [e $\varepsilon$ a] are reduced to [ə], [o o] are reduced to [u]. Unstressed high vowels are devocalized (i.e., become glides) after a vowel.

\section{Stress-assignment rule}

In this section, we analyse stress assignment within the framework of prosodic phonology that divides the representation of speech into hierarchically organised units. These prosodic constituents determine the domains of different phonological processes (Nespor and Vogel, 2007 \& Hayes, 1989a). As proposed for Greek, Latin and Turkish (Nespor and Vogel, 2007 for Greek and Latin and Kabak \& Vogel, 2001 for Turkish), this study provides arguments that the domain of stress in NK is the PW. Based on previous descriptions of Kurdish word stress which suggest that stress is placed on the word final syllable (Fattah, 1980; Qadir, 1983; Ahmed, 1986) and based on other studies for other languages which suggest that PW is the domain of stress (Nespor and Vogel, 2007 for Greek and Latin and Kabak \& Vogel, 2001 for Turkish), we will identify the PW as the domain of stress: 30- NK word stress-assignment rule: stress the final syllable of a PW.

$$
\mathrm{V} \rightarrow[+ \text { stress }] /[\ldots \ldots \ldots \ldots \ldots \text { ] }] \text { PW }
$$

Given the definition of the PW proposed in 11, this rule can be applied to (prefix)+stem+(suffix) sequence, compound words and proclitic+lexical word sequence. The following examples illustrate the rule application:

31 -

$\begin{array}{llll}\text { a- } & {[\text { 'xoş }]_{\mathrm{PW}}} & / \text { 'xof/ } & \text { (nice) } \\ \text { b- } & {[\text { xoş'tir }]_{\mathrm{PW}}} & \text { /xof'tir/ } & \text { (nicer) } \\ \text { c- } & {[\text { xoşti'rîn }]_{\mathrm{PW}}} & \text { /xofti'ri:n/ } & \text { (nicest) } \\ \text { d- } & {[\text { di'gut }]_{\mathrm{PW}}} & / \text { di'gut/ } & \text { (was saying) } \\ \text { e- } & {[\text { guneh'bar }]_{\mathrm{PW}}} & \text { /gunah'ba:r/ } & \text { (criminal) } \\ \mathrm{f}- & {[\text { ji 'mal }]_{\mathrm{PW}}} & / \text { ji 'ma:l/ } & \text { (from home) }\end{array}$

In these examples, stress is assigned to the PW ultimate syllable which might be a simple word as in (a), a sequence of a stem+suffix as in (b \& c), a sequence of prefix+stem as in (d), a compound as in (e) and a sequence of proclitic+lexical word as in (f). Examples (a-c) show that stress seems to move rightward following morphological word-formation.

An effective explanation for stress migration shown above is cyclic analysis. The following sections, a brief introduction to cyclicity will be presented, and then the way cyclic stress is assigned after every morphological operation will be explained in details. 


\section{Cyclicity}

In the word-formation process, morphological operations of a language, such as affixation and compounding, are organized into a series of levels and each level represents a domain for the application of a set of phonological rules. The output of the phonological processes becomes the input to further morphological operations (Brame, 1974; Kiparsky, 1982; Mohanan, 1982; Kaisse and Shaw, 1985; Katamba, 1989; Cole, 1995; Kiparsky, 2000). Two types of phonological rules are distinguished: lexical phonological rules which are intrinsically cyclic and applied to one or more levels in the lexicon and post-lexical phonological rules which are intrinsically non-cyclic and applied after words have been combined to form syntactic phrases (Kiparsky, 1982 and Mohanan, 1982). The cyclic application of phonological rules has been assumed to be subject to the convention of erasing internal brackets at the end of each cycle (Chomsky and Halle, 1968, also known as 'bracketing erasure' by Kiparsky (1982) and 'opacity condition' by Mohanan (1982)).

One of the phonological rules that can be applied cyclically is stress (see Chomsky and Halle, 1968 for English; Brame, 1974 for Palestinian Arabic, Maltese and Spanish; Barker, 1989 for Turkish). In English, cyclic stress assignment can be illustrated in 32 (from Chomsky and Halle, 1968: 1617):

32-

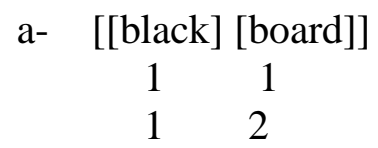

$$
\begin{array}{ccl}
\text { b- }[[\text { black }] & \text { [board }]] \\
1 & 1 & \text { Word stress cycle } \\
2 & 1 & \text { Cycle II }
\end{array}
$$

In the first line, each word is provided with the feature [1 stress] on the appropriate segment by word level stress rules. Then erasing the innermost brackets in accordance with the principle of cyclic application, we get <black board>. In (a) since <black board> is a compound noun, [1 stress] is reassigned to the [1 stress] of $\langle$ black $\rangle$ according to the English compound stress rule (assign primary stress to a primary stressed vowel to the left) and the remaining stress is reduced by one level. In (b), since <black board $\rangle$ is a noun phrase, [1 stress] is reassigned to the [1 stress] of <board $\rangle$ according to the English nuclear stress rule (assign primary stress to a primary stressed vowel to the right) and the remaining stress is weakened by one level. Thus, stress is first assigned to the inner cycle represented by the base then to the outer cycle when the base is combined with other elements after erasing the brackets. Besides, stress reassignment is coupled with the idea of stress subordination in that whenstress is placed in a certain position in a string, then all other stresses in the string are automatically reduced by one level.

Cyclic stress is also adopted by Barker (1989) for Turkish. In Turkish, stress normally falls on the word rightmost syllable and it is applied to monosyllabic and polysyllabic words and to words with suffixes, as in 33: 
33-

$$
\begin{array}{lll}
\text { a- } & \text { taní } & (\text { know) } \\
\text { b- tani-dík } & \text { (acquaintance) } \\
\text { c- tani-dik-lár } & \text { (acquaintances) } \\
\text { d- tani-dik-lar-ím } & \text { (my acquaintances) } \\
\text { e- tani-dik-lar-im-íz } & \text { (our acquaintances) }
\end{array}
$$

Barker (1989) proposed that stress is applied cyclically in that after suffixation the rule is reapplied and stress migrates to the final syllable of the newly formed word. He adopted Hayes' $(1985,1987)$ metrical theory, in which stress is presented as a hierarchically organised rhythmic structure. The relative prominence of the syllables of a word is indicated by a metrical grid of ' $x$ 's which is a sequence of beats (grid columns) equally spaced in time and which vary in strength according to their height. Syllables with more ' $x$ 's are more prominent with respect to stress. For example, in $\langle$ tani $\rangle$ the first cycle is the bare stem in which stress is applied to the final syllable and the output is $\langle$ tani $\rangle$. After the suffixation of $\langle d i k\rangle$ in the second cycle, the stress is reapplied and the output is $\langle$ tani-dik $\rangle$ with the stress on the final syllable. Besides, Baker proposed the stress clash resolution rule which is used to resolve the stress clash created by two adjacent syllables with equal prominence by deleting the leftmost clashing element. The cyclic stress and stress clash resolution can be illustrated in 34 (from Baker, 1989: 9):

34- First cycle Default stress

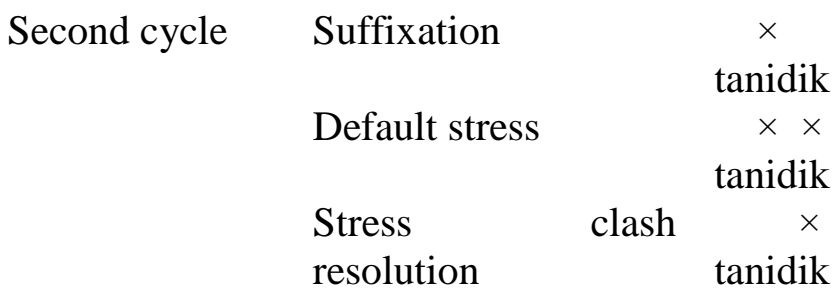

This study assumes that Kurdish has a lexical phonology of the type suggested by Kiparsky (1982) and Mohanan (1982) above. The application of word formation rules induces the application of phonological rules, i.e. phonological rules apply directly after every morphological operation. The derivation of the word <gundiyan > /gundija:n/ (villagers) is an example:

$35-$

$\begin{array}{ll}\text { gund } & \text { stem } \\ \text { [[gund] î ] } & \text { affixation } \\ \text { [[gun] dî ] } & \text { resyllabification } \\ \text { [[gun] dî ] an ] } & \text { affixation } \\ \text { [[gun] dî ] yan ] } & \text { glide insertion }\end{array}$

As in languages such as English, Palestinian Arabic and Turkish, we argue that the stress in NK can be applied cyclically within the PW-domain. In other words, stress is invariably assigned to the PW ultimate syllable following every morphological word-formation process. Earlier works on 
Kurdish stress (Fattah, 1980; Qadir, 1983 and Ahmed, 1986) claimed that stress is assigned to a word as a whole after all morphological operations have taken place which leaves many exceptions. As for Turkish for the representation of stress, we adopted Hayes' (1995) metrical grids which consist of a sequence of grid markers ' $x$ ' equally spaced in time and which vary in strength according to their height. The cyclic application of stress in Kurdish can be illustrated by the word <grantirîn> /gra:ntiri:n/:

$36-$

$\begin{array}{lll}\text { Cycle I } & \text { Stress rule } & \times \\ & & \text { gran (expensive) } \\ \text { Cycle II } & \text { Suffixation } & \text { grantir (more expensive) } \\ & \text { Stress rule } & \times \\ & & \times \\ & & \text { grantir } \\ \text { Cycle III } & \text { Suffixation } & \text { grantirîn (most expensive) } \\ & \text { Stress rule } & \times \\ & & \times \\ & & \times \times \\ & & \\ & & \text { grantirîn }\end{array}$

The first cycle is the word-level stress in that the stem $\langle$ gran $\rangle$ is produced with one primary stress. After the suffixation of $\langle$ tir $\rangle$ we get $\langle$ grantir $\rangle$, stress is reapplied and it moves rightward to be placed on the suffix. In the third cycle, in the formation of 〈grantirin $\rangle$, the stress is again moved rightward to be placed on the suffix $\langle\hat{i n}\rangle$. This pattern illustrates stress migration, i.e. stress moves rightwards with each successive suffixation and in each case other levels of stress on the left are weakened by one level.

As in Turkish, the motion of the stress rightwards results on the creation of two adjacent stresses (stress clash). To resolve this clash, we adopted Hayes' (1995: 36-37) 'destressing in clash' rule which involves the removal of one stress on a syllable adjacent to another one and if the two stresses are unequal in strength, it is always the weaker that is removed according to the continuous column constraint which implies 'make the weak weaker'. The continuous column constraint means that if a syllable forms a rhythmic beat on a given layer, it must also form rhythmic beats on all lower layers (Hayes, 1995: 34). Thus, for two adjacent stresses it is only the weaker that is deleted because the deletion of a stronger stress would create a discontinuous column. So in Kurdish, the destressing rule involves the deletion of the leftmost clashing element in a stress clash.

37- Destressing rule: $\times \rightarrow \varnothing /$

Thus the stress clash observed in second and third cycles of the cyclic stress application in <grantirin > can be resolved as follow:

38-

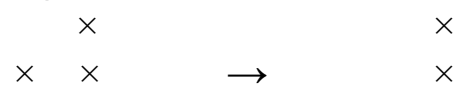




\begin{tabular}{|c|c|c|c|}
\hline granti & & & grantir \\
\hline & $x$ & & $x$ \\
\hline$x$ & $x$ & $\rightarrow$ & $x$ \\
\hline $\begin{array}{l}\times \times \\
\text { granti }\end{array}$ & $\begin{array}{l}\times \\
\text { rîn }\end{array}$ & & $\begin{array}{c}\times \times \times \\
\text { grantirîn }\end{array}$ \\
\hline
\end{tabular}

Aother example of the cyclic rule application in Kurdish is:

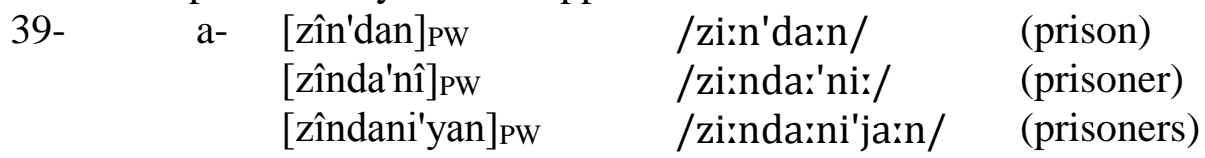

Also, in compound as in complex words, stress can be applied cyclically. Example 40 illustrates the cyclic stress in the compound <tevin pirk>: 40-

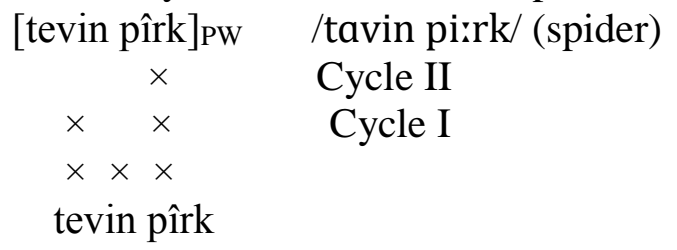

The first cycle indicates the word-level stress in which each word is assigned a stress following the word-stress rule. In $\langle$ tevin $\rangle$, the first syllable is stressed and $\langle$ îrk $\rangle$ is a monosyllabic word produced with stress. When the innermost brackets are erased, we get <tevin pirk> in the second cycle which is a compound noun. We assign stress to the rightward element, i.e. 〈pirk> according to the stress rule stated in (30).

Thus, on the basis of the stress rule, the members of a compound form a single $\mathrm{PW}$. The first indication is that compounds as other types of words bear only one primary stress i.e. only the stress of the final component word is reserved, whereas the stress of other components are reduced. Examples:
41- a- gu'neh+'bar
[guneh 'bar] $]_{\mathrm{PW}}$
/gunah'ba:r/
(criminal)
b- 'rast+'gu
[rast 'gu $]_{\mathrm{PW}}$
/rasst'gu/
(honest)

This result confirms Qadir (1983) and Ahmed's (1986) statement that in compounds stress is placed on the final syllable of the second word and secondary stress is placed on the last syllable of the first word. The second indication is that the two members of a compound follow the same stress rule stated in (30). In other words, similar to simple and complex words, in a compound stress is applied to the last syllable of the last component word. A similar case is observed for Greek (Nespor \& Vogel, 2007) in which the compounds form one PW since they have only one stress and they must respect the same well-formedness condition that applies to stress in simple words, i.e. stress must fall on one of the last three syllables of the compound.

In conclusion, stress is one of the phonological rules that occur within the PWdomain. According to the rule, stress is assigned to the PW ultimate syllable. The rule is applied cyclically in that stress tends to move rightward in every morphological operation. 
However, closer examination of our data reveals several exceptions to the stress rule (30) where stress is not assigned to the PW final syllable. We argue that these cases represent exceptions to the main stress rule. In the following section, we will explain that these exceptions result from stress shift. In other words, we argue that stress shift is a phonological rule that occurs when stress is moved from its rule-based position.

\section{Stress-shift rule}

This section will discuss stress-shift in NK. Stress-shift has been given considerable attention in English (Liberman and Prince, 1977; Hayes, 1995; Grabe \& Warren, 1995). Generally, it refers to stress movement away from its rule-based position. It can be caused in order to avoid stress clash (Liberman and Prince, 1977). In English, when there is a disruption to the preferred stressed-unstressed alternations, stress-shift is used to restore this pattern by moving the first of the adjacent prominences into an earlier full-vowel syllables within the same lexical item, and thereby reversing the prominence distribution within the stress-shift item (Grabe \& Warren, 1995). For example, when a word such as <thir'teen>, with two full vowels and the strongest prominence on the last stressed syllable is closely followed by a stressed item, e.g. a monosyllabic word with primary stress such as $\langle m e n\rangle$, the stresses clash and as the result the stress of <thirteen> is reversed, producing <'thirteen 'men> as illustrated in 42 (Liberman and Prince, 1977).

42- a-

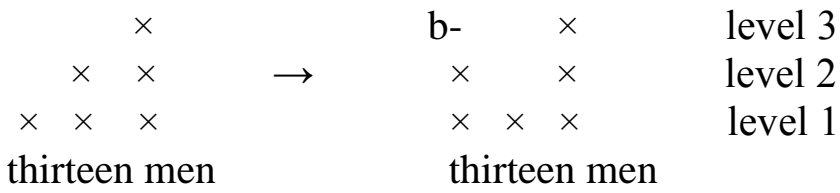

Furthermore, stress may shift because of the occurrence of some phonological processes. For example, in Arabic vowel reduction and low vowel deletion rules may lead to stress-shift. According to Prince (1975) in classical Arabic the penultimate stress in /kaa'tabuu/ is shifted under vowel reduction to yield /kaatə'buu/. This can be interpreted that vowel reduction to schwa automatically shifts stress rightward. Additionally, Al-Mozainy, Vroman and McCarthy (1985) described stress shift phenomena as a result of low vowel deletion in Bedouin Hijazi Arabic. According to this rule, short/a/ in an open syllable is deleted if it is followed by an open syllable that contains short /a/: a $\rightarrow \emptyset / \mathrm{C}-[\mathrm{Ca}] \sigma$, as in 43: (from Al-Mozainy, Vroman and McCarthy, 1985: 135) 43-
a- 'sahab
(he pulled)
sh'abaw
(they pulled)
b- 'naxal
(palm trees) nx'alah
(a palm tree)

The stress rule in Arabic states that if the ultimate syllable or the penultimate syllable are not heavy or super-heavy, stress falls on the antepenultimate syllable. Thus, in the examples (43) when the inflectional 
suffix $\langle-a w\rangle$ (a) or the plural ending $\langle-a h\rangle$ (b) are attached, stress falls on the antepenultimate. However, according to the low vowel deletion rules short $\mathrm{la} /$ is deleted in the antepenultimate and stress shifts to the penultimate since the landing site is no longer available and the remaining consonant forms a cluster with the onset of the following syllable.

Compared to English, where stress shift is determined by the stress patterns of the surrounding elements, and Arabic, where the occurrence of phonological processes triggers stress shift, stress shift in NK is the result of phonological, morphological or syntactic conditions. First, it is observed that the phonological type of the PW final syllable has an effect on the stress movement leftward. Second, stress may be determined by morphological factors such as the existence of some affixes which block the cyclic application of stress and prevents the migration of stress to the PW right-edge. Finally, stress may shift to a landing site earlier in a PW to achieve some syntactic functions. In the following sections, phonologically-governed stress shift is discussed, recursivity and phrase stress rule account for the cases of morphologically-governed stress-shift and finally syntactically-governed stress-shift is presented.

\section{Phonologically-governed stress-shift}

This section introduces the syllable weight priciple and then the effects of syllable weight on stress-shift in Kurdish will be discussed.

According to weight priciple, syllables are classified into light and heavy. A light syllable has a short vowel in the rhyme, whereas a heavy syllable has a long vowel, a short vowel plus coda or a long vowel plus coda. Heavy syllables characteristically attract stress, whereas light syllables receive stress only in the absence of a heavy syllable (Hayes, 1995). However, the weight system is language-specific. Some languages class closed syllables and long-voweled syllables as heavy, for instance, Latin. Other languages classify long-voweled syllables as heavy and short-voweled syllables as light, irrespective of whether they are closed, e.g. St. Lawrence Island Yupik, Lenakel. Some other languages like Hixkaryan, a Caribean language of Northern Brazil with no length contrast in the vowel inventory classifies CVC as heavy and CV as light syllables (Hayes, 1995).

Different approaches to syllable weight exist. First, in the theory of syllabic constituency (Levin, 1985 cited in Hayes, 1995), the syllable is assigned a particular internal constituent structure and only certain constituents may be prosodically active. The weight criterion that counts vowel length only may be characterised as branching versus non-branching nucleus and rhyme. So a light syllable contains a non-branching nucleus whereas a syllable with a long vowel is interpreted as heavy because its nucleus branches. For example, Hayes (1995: 51) states that /ta/ is light 
because the nucleus is not branching: there is one segment in the nucleus and rhyme, whereas /ta:/ has two segments in the nucleus and rhyme: it is branching, so it is heavy.

The second theory postulates explicit units of weight called moras $(\mu)$ (Hayes, 1989b). In this approach, the segments that are prosodically active are assigned a mora. For example, /ta/ is light because one mora is assigned to the nucleus, whereas /ta:/ is heavy because two moras are assigned to the nucleus. There are cross-linguistic differences in the criterion of syllable weight which is expressed by language-specific conditions on mora assignment. For example, languages like Latin allow postvocalic consonants within the syllable to bear a mora whereas languages like St. Lawrence Island Yupik do not (Hayes, 1995). According to weight criteria, syllables in Kurdish are classified as follow:

\begin{tabular}{|c|c|c|}
\hline Light & Heavy & Superheavy \\
\hline $\mathrm{CV}$ & VC CCVC CV: CVC & $\begin{array}{lcc}\text { CVCC } & \text { CV:C } & \text { CCV:C } \\
\text { CCVCC } & \text { CCV:CC } & \end{array}$ \\
\hline
\end{tabular}

Superheavy syllables are mostly restricted to word final position and some structures, such as CCV:C, CCVCC and CCV:CC do not appear in multisyllabic words. Following work by Steriade (1991 cited in Gordon, 2002) that all segments in the rime are treated as moraic, reflecting their potential weight-bearing status, we assign explicit units of syllable weight, moras, to the syllable structures identified for Kurdish. CV syllables are assigned one mora, as in (44a), VC, CCVC, CV: or CVC are assigned two moras, as in (48b), while CVCC, CV:C, CCV:C, CCVCC or CCV:CC are assigned two moras plus one or two stray $\mathrm{C}$, as in (44c). Kurdish assigns a mora to a postvocalic consonant within the syllable because it contributes to syllable weight as it is clear as in $\langle e v\rangle$ and $\langle$ frot $\rangle$ below. Accordingly, Kurdish has a weight by position which is a term used by Hayes (1989b) to refer to the assignment of moras to postvocalic consonants. Additionally, as in most languages (except languages such as Piraha (Hayes, 1995)), in Kurdish onset consonants are not licensed moras.

44- a-

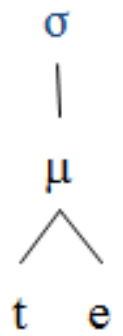


b-
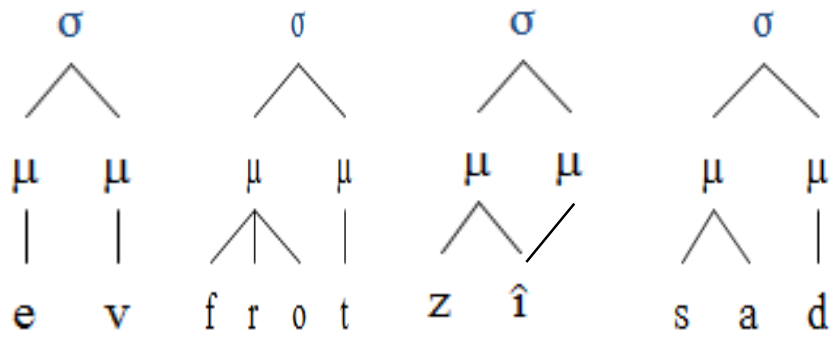

$\mathrm{z} \hat{\mathbf{1}}$

s a d

$\mathrm{c}-$
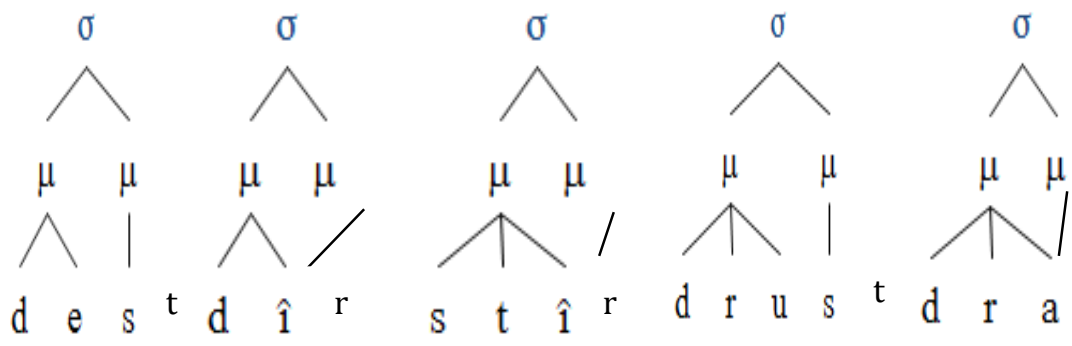

$\mathrm{s}$

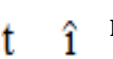

d $\quad r \quad u \quad s \quad t$

nd

Previous studies on the Kurdish stress have neglected the concept of syllable weight. However, our examination of Kurdish data revealed several cases in which stress is shifted to the penultimate syllable because of the weight of the ultimate and penultimate syllables.

When the ultimate syllable is open and light and the penultimate is heavy, stress is shifted leftwards to the penultimate, as in:

45- CV:/ CV:C/ CVC $\rightarrow[+$ stress $] /[\ldots$. $\mathrm{CV}]_{\mathrm{PW}}$

The rule does not apply when both ultimate and penultimate are open and light and stress remains on the ultimate syllable following the default rule. In the following examples, stress is shifted to the penultimate because it is a heavy open syllable, in comparison to the last syllable which is light.
46-

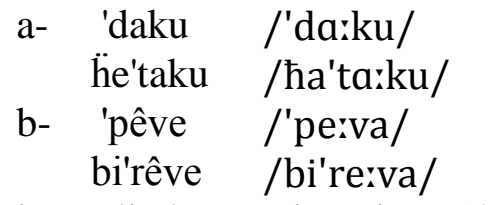
da.ku
$\mathrm{CV}: / \mathrm{CV}$
(in order)
he.ta.ku
$\mathrm{CV} / \mathrm{CV}: / \mathrm{CV}$
(until)
pê.ve
$\mathrm{CV}: / \mathrm{CV}$
(stick to it)
bi.rê.ve
$\mathrm{CV} / \mathrm{CV}: / \mathrm{CV}$
(on the way)

This rule is applied to conjunctions (46a) and adverbs (46b). It is not applied to nouns (47) even though the same weight conditions occur.
47-

frukxa'ne
/frukxa:'na/
fruk.xa.ne
$\mathrm{CCVC} / \mathrm{CV}: / \mathrm{CV}$
(airport)
$\mathrm{CVC} / \mathrm{CV}: / \mathrm{CV}$
(identity)

In 48 , stress is shifted from the final syllable to the penultimate because the final is open light and the penultimate is heavy closed or super-heavy.

$\begin{array}{cllll}48 \text { a- 'evru } & \text { /'avru/ } & \text { ev.ru } & \text { VC/CV } & \text { (today) } \\ \text { 'pêkve } & \text { /'perkva/ } & \text { pêk.ve } & \text { CV:C/CV } & \text { (together) } \\ \text { ji'derve } & \text { /ji'darva/ } & \text { ji.der.ve } & \text { CV/CVC/CV } & \text { (outside) } \\ \text { b- 'çunke } & \text { /'funka/ } & \text { çun.ke } & \text { CVC/CV } & \text { (because) } \\ \text { 'belku } & \text { /'balka/ } & \text { bel.ku } & \mathrm{CVC} / \mathrm{CV} & \text { (but) }\end{array}$




\section{c- 'fermu /'farmu/ fer.mu CVC-CV (yes) \\ ke'remke /ka'ramka/ ke.rem.ke CV/CVC/CV (come in)}

The rule is applied to adverbs (examples 48a), conjunctions (48b) and interjections (48c). It is not applied to nouns (examples 49a) and adjectives (49b) even though the same weight constellation occurs.

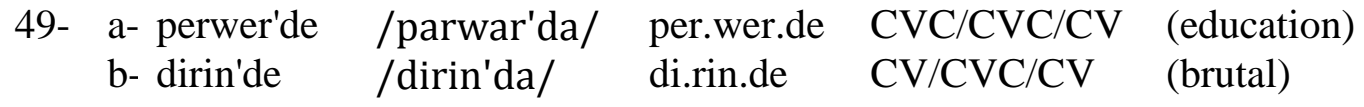

Thus, within the PW-domain, stress is shifted from the final syllable to the penultimate if the penultimate is heavy or super-heavy.

However, stress shift in NK is not limited to open light ultimate syllables. It also occurs when the ultimate is heavy but only if they are open syllables and preceded by a closed heavy or super-heavy penultimate as in 50 .

$\begin{array}{rlllll}\text { 50- a- } & \text { 'kengî } & \text { /'kangi:/ } & \text { ken.gî } & \text { CVC/CV: } & \text { (when) } \\ & \text { 'çenda } & \text { /'tanda:/ } & \text { çen.da } & \text { CVC/CV: } & \text { (how) } \\ \text { b- } & \text { 'hêşta } & \text { /'he:fta:/ } & \text { hêş.ta } & \text { CV:C/CV: } & \text { (not yet) } \\ & \text { 'tenha } & \text { /'tanha:/ } & \text { ten.ha } & \text { CVC/CV: } & \text { (only) }\end{array}$

In these cases, although the ultimate is heavy, stress is shifted to the penultimate. The rule is applied to question words (50a) and adverbs (50b). It is not applied to verbs (50a), nouns (50b) and adjectives (50c).

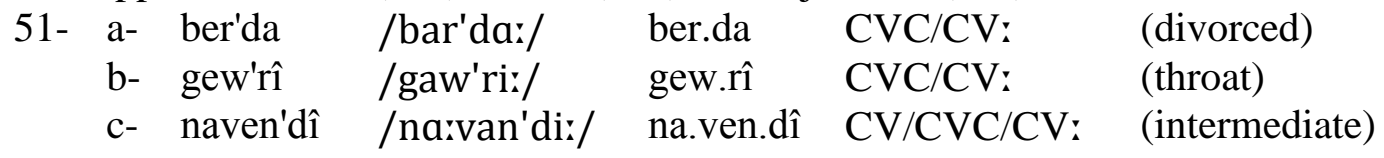

This means that final CV: when preceded by a heavy or super-heavy syllable is counted as light not heavy. To account for this case, we will apply the notion of extrametricality.

Extrametricality is a process which 'designates a particular prosodic constituent as invisible for the purposes of rule application: the rules analyse the form as if the extrametrical entity were not there' (Hayes, 1995: 57). For example, Estonian has a complex stress that distinguishes between light (CV) and heavy (CVC, CV: CVCC) syllables. Word finally, a special classification of heavy versus light is used, i.e. the final $\mathrm{CVC}$ is counted as light rather than heavy. Thus the final consonant of the CVC word finally is ignored or become extrametrical and the notation $\langle>$ is used to indicate extramerticality $\mathrm{CV}\langle\mathrm{C}\rangle$. Hayes (1995: 57) proposed some restrictions on extrametricality: 1) constituency: only constituents (segment, syllable, foot, PW, affix and mora) may be made extrametrical, 2) peripherality: a constituent is made extrametrical only if it is on the left or right-edge of its domain, 3) edge markedness: the unmarked edge for extrametricality is the right and 4) nonexhaustivity: extrametricality is not applied if it would render the entire domain of the stress rules extrametrical.

In NK, in PW-final position a special distinction is made between heavy and light syllables depending on the preceding syllable. According to 
the moraic theory of syllable, heavy syllables are assigned two moras while a light syllable is assigned only one mora. Thus, CV: is assigned two moras because it is considered heavy. However, when this syllable type occurs in PW-final position preceded by a heavy syllable, the second or right edge mora in the final syllable of a PW is made extrametrical, i.e. the vowel length in the PW final CV: when preceded by CVC or CV:C goes unrealised and it is counted as light rather than heavy. The extrametricality can be shown as in 52 :

$52-$

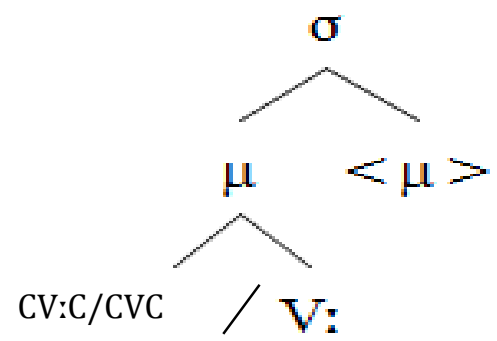

A similar analysis had been applied to Cairene Arabic by Hayes (1995). Long-voweled syllables in Cairene Arabic are assigned two moras. Word finally, the second mora of a long vowel is made extrametrical and vowel length distinctions word finally normally go unrealised in the pronunciation.

Thus in NK, mora counts seem relevant in the stress assignment in adverbs, conjunctions, question words and interjections. In these constituents, the final syllable has to be heavy in order to receive stress i.e. it is assigned two moras. If the final is light in which case it is assigned only one mora, stress shifts to the penultimate. Hence, final CV: when preceded by a closed heavy or super-heavy syllable is assigned one mora, the final mora is made extrametrical and stress is shifted to the penultimate. Meanwhile, final CVC is accounted heavy in NK. The rule can be formulated in 53:

53- $\mathrm{CVC} / \mathrm{CV}: \mathrm{C} \rightarrow[+$ stress $] /[\ldots$. $\mathrm{CV}:]_{\mathrm{PW}}$

The fact that final CV: is not stressed can be further reinforced in cases where the penultimate is also $\mathrm{CV}$, since stress is shifted to the penultimate as in 54:

$\begin{array}{rllll}\text { 54- a- 'gava } & \text { /'ga:va:/ } & \text { ga.va } & \mathrm{CV}: / \mathrm{CV}: & \text { (when) } \\ \text { 'paşî } & \text { /'pa:fi:/ } & \text { pa.şî } & \mathrm{CV}: / \mathrm{CV}: & \text { (after that) } \\ \text { b- 'dîsa } & \text { /'di:sa:/ } & \text { dî.sa } & \mathrm{CV}: / \mathrm{CV}: & \text { (again) } \\ \text { 'têda } & \text { /'te:da:/ } & \text { tê.da } & \mathrm{CV}: \mathrm{CV}: & \text { (inside) }\end{array}$

The rule is applied to conjunctions (54a) and adverbs (54b). The rule can be formulated as:

55- CV: non-final $\rightarrow[+$ stress $] /\left[\ldots \ldots \_C V:\right]_{\mathrm{PW}}$ 
A third case is when the final syllable is heavy closed but its nucleus is the vowel /i/. Also here stress is shifted to the penultimate even if it is open light (Fattah, 1980 and Mosa, 2009), as illustrated in 56:

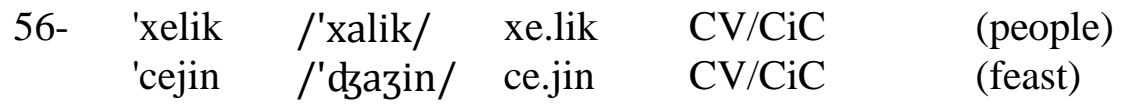

The vowel /i/ is called 'furtive $i$ ' by Thachston (2006: 5) which appears when an intolerable final two consonants cluster appears, the consonants are separated by /i/. This vowel appears when words containing the cluster are in isolation or when followed by a consonant-initial suffix and disappears when followed by a vowel-initial suffix. In other words, when a vowel-initial suffix is added, the coda of the CiC syllable becomes the onset of the suffix, /i/ is dropped and the onset is resyllabified as the coda of the preceding syllable as in 57:

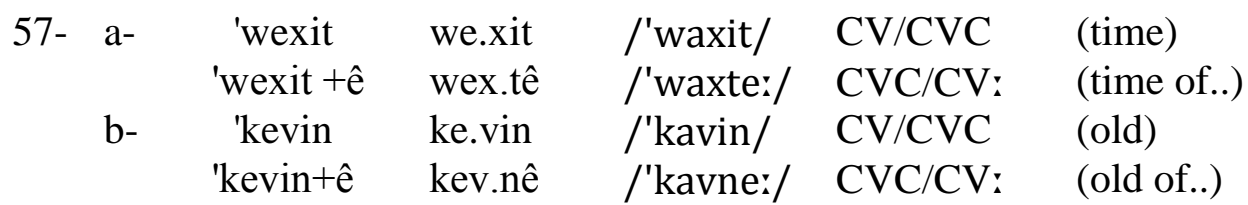

Thus, this case of the stress-shift rule can be summarised as: $58-\mathrm{V} \rightarrow[+$ stress $] /[\ldots \ldots \mathrm{CiC}]_{\mathrm{PW}}$

The rule implies that when the nucleus of the final syllable is /i/, stress is shifted to the penultimate regardless of its weight.

The first two cases provide evidence that relative syllable weight has an effect on stress in NK, i.e. stress-shift is triggered by the relative weight relationship between the ultimate and penultimate. The third case provides evidence for the relevance of the segmental content to stress in that syllables with /i/ are usually unstressed (except in the case of the stressed imperative prefix $\langle b i\rangle$ and the infinitive suffix $\langle i n\rangle$ ). /i/ is very weak in Kurdish since it only occurs in unstressed syllables and is mostly deleted. When it is deleted resyllabification is triggered. Thus, stress-shift occurs within the PW-domain and represents an exceptional rule to the stress rule (30). This vowel is comparable to the vowel schwa /a/ in English. Schwa is a reduced vowel and usually occurs in unstressed syllables (Chomsky and Halle, 1968).

\section{Recursivity}

NK has a class of non-stress bearing suffixes. These suffixes block the cyclic application of stress, i.e. PW-final stress does not reapply after their affixation. For example, in <mêvan> and <zêrevan>, stress is placed on the ultimate syllable. In the oblique case, when the gender marker suffix $\langle\hat{\imath}\rangle$ is added, the stress rule is violated because it fails to reapply because of $\langle\hat{\imath}\rangle$. 
$59-$

$\begin{array}{cccc}\times & \text { Cycle II } & \times & \text { Cycle II } \\ \times & \text { Cycle I } & \times & \text { Cycle I } \\ \times \times \times & & \times \times \times \times & \\ \text { mê'vanî/me:'va:ni:/ } & \text { zêre'vanî /ze:ra'va:ni:/ }\end{array}$

In these examples, stress is placed on the second syllable in 〈mêvan > and the third in <zêrevan > in the first cycle and the stress remains in the same position in the second cycle because of the suffixation of the non-stress bearing suffix $\langle\hat{\imath}\rangle$.

Only few suffixes which block the PW-final stress rule can be found in Kurdish (see the introduction section for the list of these suffixes). The general characteristics of these suffixes are that they are inflectional, monosyllabic and they are either vowel-initial or consist of a vowel only. Thus, when they are attached to a consonant-final stem, resyllabification is triggered or when added to a vowel-final stem, GI occurs.

We argue that the best analysis to account for these exceptions is recursive structure, in which one PW exists inside another PW. In prosodic phonology, it is claimed that the constituents in a prosodic hierarchy have a recursive structure, i.e. when one prosodic constituent dominates another constituent of the same rank, for example a foot dominates another foot (Selkirk, 1995, Booij, 1996 and Ito \& Mester, 2009 \& 2012). Recursivity, also called level repetition, has proposed for different phonological levels: the intonational phrase (Ladd, 1986), the phonological phrase (Gussenhoven, 2005) and the prosodic word (Ito \& Mester, 2009).

Recursive structure has proposed for the PW for many languages such as English and German (Ito \& Mester, 2009), Persian (Hosseini, 2011, 2014). In English, function words such as prepositions and determiners are treated as dependent elements within an extended PW, where it has adjoined to a core PW, its head, as it is illustrated in the diagram for <to Rhodes $>$ in 60:

$60-$

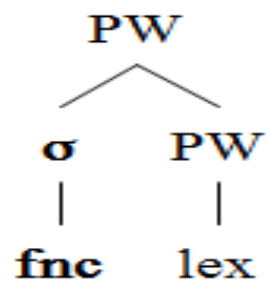


In Persian (Hosseini, 2011, 2014), enclitics are grouped with their hosts in a recursive structure. In recursive PWs, The lower PW, which does not dominate any other PW, is called a minimal PW, and the higher PW, which is not dominated by any other PW, is called a maximal PW. Syllabification is obligatory in the maximal PW, and stress is also obligatory and culminative in this domain. Minimal PW are always right-aligned with a lex and stress is rightmost in their domain.

In NK, suffixes that never bear stress are mostly inflectional and behave as prosodic clitics which are considered as prosodically weak function words (fnc) which cannot form PWs in themselves because they are stressless (as discussed in Selkirk 1995 and Ito and Mester 2009). The lexical host (lex) comprises the minimal PW, and the clitics are treated as adjoined elements to a core PW which together are dominated by the maximal PW. The necessity of all elements to be parsed at PW level will eventually parse fncs to PWs in a recursive structure, resulting in the following structure:

61- [ [lex $\left.]_{\mathrm{PW}}[\mathrm{fnc}]\right]_{\mathrm{PW}}$

Stress is rightmost in the minimal PW and it is also obligatory and culminative in the maximal $\mathrm{PW}$, while the processes of resyllabification, vowel shortening, glide insertion occur in all PWs. Thus, the examples in 59 can be analysed as:

62- a- [ [mê'van $\left.]_{\mathrm{PW}}[\hat{1}]\right]_{\mathrm{PW}}$

b-[ [zêre'van $\left.]_{\mathrm{PW}}[\hat{1}]\right]_{\mathrm{PW}}$

So the obligatory syllabification of host+enclitic combinations in NK suggests that there is no PW boundary between a host and its enclitic. Another evidence that fnc are adjoined to a PW is GI. Adjacent vowels are also avoided when the first of two vowels is the final vowel of a lex and the second one is the initial vowel of a fnc. In this case, a glide is inserted between the two vowels to resolve the hiatus, as it is illustrated in:

63- [qotabîi] $]_{\text {lex }}[\mathrm{ek}]_{\mathrm{fnc}} \rightarrow$ qotabîyek ( a student)

Student IND

Finally, the phonetic content or the vowel type is not the reason behind the blocking because there exist some suffixes with the same phonetic content but they do not block the stress rule, namely the infinitive <-in> (64a) and the derivational $\langle-\hat{\imath}\rangle$ which is used to drive nouns from adjectives (64b).

64-

$$
\begin{aligned}
& \text { a- 'hat }+ \text { in ha'tin /ha:'tin/ (to come) } \\
& \text { b- 'xoṣ+în } \quad \text { xo'ṣ̂ি /xo'fi:/ (happiness) }
\end{aligned}
$$

\section{Phrasal stress}

Additionally, there are some verbal prefixes which also pose a problem for the PW-final stress. These prefixes are identified as stress bearing in that they attract stress themselves after their affixation. Two types of stress-bearing 
prefixes have previously been identified (Fattah, 1980, Qadir, 1983): the imperative $\langle b i-\rangle$ and negative markers $\langle n e-\rangle$ and $\langle n a-\rangle$.

To resolve this problem, we propose that a distinction should be made between word-level and phrase-level stress in NK. We argue that there is a phonological level above the PW level which is called the phonological phrase (PP) which is made up of one or more PWs. The phrase stress falls on the first PW in the PP. In NK, verb phrases are treated as PPs. The verbal prefixes indicating mood markers and negative markers form separate PWs within a PP. These prefixes are inflectional elements and thus they function as separate PWs. Thus, The prosodic constituent of the PP is shown as:

$65-\left[[\mathrm{X}]_{\mathrm{PW}}[\mathrm{X}]_{\mathrm{PW}}\right]_{\mathrm{PP}}$

Henceforth, <nekoŝt $\rangle$ /'nakoft/ (he did not kill him) and <bibe >/'biba/ (take it) are considered PPs in NK and their prosodic constituency is shown in:

66- a- [ ['ne-] PW [koŝt] PW ]PP

b-[ ['bi-] PW [be] PW ]PP

In these examples, each PW receives a primary stress according to the stress rule (in 30). At the phrasal level, stress falls on the leftmost PW. As a result the stress of the whole phrase falls on the first PWs which are $\langle n e-\rangle$ and $\langle b i\rangle$ respectively.

A similar analysis is proposed for Persian by Kahnemuyipour (2003). He states that verbal prefixes are PWs and the phrase level stress rule in Persian (the first PW in the PP takes stress) puts the stress on the initial PW in the PP which are the prefixes, as in 67 (from Kahnemuyipour, 2003: 344):

67-a- [ ['mî-] PW [xar $\left.]_{\mathrm{PW}}\right]_{\mathrm{PP}}$ indic-buy-3SING

b- [ ['na- PW $\left._{\mathrm{P}}[\mathrm{xarid}]_{\mathrm{PW}}\right]_{\mathrm{PP}}$

NEG-bought-3SING

The affixes may form independent PWs has been argued for other languagessuch as Italian (Nespor and vogel, 2007).

Furthermore, a similar analysis can be applied to complex verbs with preverbs. It is claimed that in complex verbs with preverbs such as $\langle v e\rangle$, $\langle w e r\rangle,\langle h e l\rangle$ and $\langle d a\rangle$, stress falls on the preverbs (Thackston, 2006), as in:

\begin{tabular}{|c|c|c|c|}
\hline $68-$ & 'vexar & /'vaxarr/ & $\begin{array}{l}\text { drink-PAST-3 } 3^{\text {rd }} \text { SING } \\
\text { (He drank) }\end{array}$ \\
\hline b- & 'wergêrand & /'warge:ra:nd/ & $\begin{array}{l}\text { translate-PAST- } 3^{\text {rd }} \text { SING } \\
\text { (He translated) }\end{array}$ \\
\hline$c-$ & 'helgirtin & /'halgirtin/ & $\begin{array}{l}\text { take-PAST-3 }{ }^{\text {rd }} \text { PL } \\
\text { (They took) }\end{array}$ \\
\hline d- & 'danan & /'da:na:n/ & $\begin{array}{l}\text { put-PAST- } 3^{\text {rd }} \text { PL } \\
\text { (they put) }\end{array}$ \\
\hline
\end{tabular}


We argue that these complex verbs also constitute PPs in NK in which the preverbs are treated as separate PWs and according to the phrasal stress rule, stress is placed on the first PW, here the preverb. Thus, the prosodic constituency of the examples in 68 will be analysed as follow:

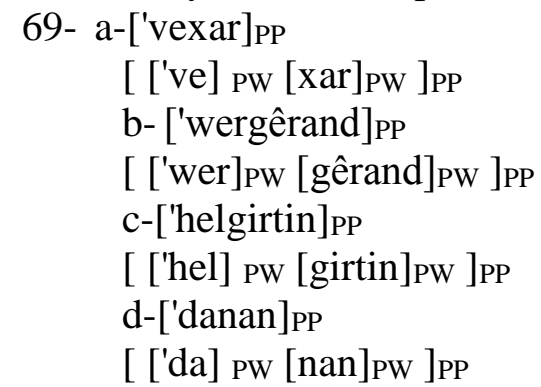

A similar case had been identified for Persian by Kahnemuyipour (2003). He analysed conjugated verbs to be PPs rather than PWs in Persian. Besides, he considered each morpho-syntactic element inside the verb as a PW and stress is rightmost inside PWs and leftmost inside PPs, as in:

70- [ ['be] PW [xar] PW -am]PP

sub. -buy- 1 SING

\section{Syntactically-governed stress shift}

It is found that syntactic factors may affect stress and lead to stress shift from its rule-based position to another position in a word to achieve some syntactic functions (Fattah, 1980). For instance, the imperative mode can be expressed by the prefix $\langle b i-\rangle$ and the addition of number markers, or by the stress-shift to the initial syllable of the verb in the case of the absence of any morphological markers (Majid, 1987), as illustrated in 71:

\begin{tabular}{|c|c|c|c|}
\hline 71- & $\begin{array}{ll}\text { a- } & \text { 'saxke } \\
\text { b- } & \text { 'dîrke }\end{array}$ & $\begin{array}{l}\text { /'sa:xka/ } \\
\text { /di:rka/ }\end{array}$ & $\begin{array}{l}\text { (treat him) } \\
\text { (keep it away.) }\end{array}$ \\
\hline
\end{tabular}

Another case in which the stress-shift is syntactically-governed is the vocative case. When a polysyllabic proper noun is used in direct address, stress moves from the final syllable to the first or in the case of common nouns by stress-shift to the word initial position and by the addition of suffixes $\langle-o\rangle$ for singular masculine, $\langle-\hat{e}\rangle$ for feminine and $\langle-(i) n o>$ for plural (Fattah, 1980 and Thackston, 2006). For example,

$72-$
a- 'sayran
(you sayran) say'ran (picnic)
b- 'da $+\hat{e}$ (dayê) (mother)
c- 'kur + o (kuro) (you boy)
d- 'bra+no (brano) (you brothers)
e- 'heval+ino (you friends)

In the first example, it is clear that there is also a change in meaning in that <sayran> as a noun has a different meaning (a picnic) and stress pattern from that when they are used as vocatives. This type of stress shift is used to 
show lexical distinction which is rare in some languages but do occur even in intonation languages such as English as in <'subject - sub'ject>.

\section{Conclusions}

The study presented a unified description of stress in NK. First, comparable with languages like Greek, Latin (Nespor and Vogel, 2007), Turkish (Kabak and Vogel, 2001) and Catalan, the PW is identified as the domain of stress. The structure of the PW is identified and it represents the domain of a number of phonological rules which provide evidence for its existence. The Kurdish PW behaves similar to Dutch and English PWs, i.e. it is larger than a grammatical word. The introduction of the PW in NK is important because as stated it is identified as the domain of certain phonological processes. Additionally, a better understanding of the PW provides insights into the interaction between phonology and morphology by illustrating the way the PW is constructed on the basis of information on the internal structure of morphological words.

It is proposed that the stress in NK falls on the PW final syllable. Earlier works on Kurdish stress (Fattah, 1980; Qadir, 1983 and Ahmed, 1986) claimed that stress is assigned to a word as a whole after all morphological operations have taken place. In this study, it has been argued that it is applied cyclically so that stress can be reassigned to the PW-final syllable following each level of morphological word-formation. Cyclic application of the stress rule has previously been proposed for several languages such as English (Chomsky and Halle, 1968), Palestinian Arabic, Maltese and Spanish (Brame, 1974) and Turkish (Barker, 1989). Generally, the PW must bear one and only one stress and consequently elements which cannot bear stress will not count as PWs, for example clitics and first elements of compounds are incorporated into single PWs. However, in verb phrases stress bearing prefixes and preverbs are counted as separate PWs because they are stressed. In addition, we identified the exceptions of the stress rule proposed here as a phenomenon of stress-shift which occurs within the PW domain. According to this rule, stress may shift from the default position, i.e. the PW-final syllable for different factors such as phonological, morphological or syntactic factors. The study focused on phonologically and syntactically-conditioned stress shift and cases of morphologically conditioned stress shift are accounted for by recursive structures and phrase stress rule. This analysis of stress differs from other analyses in that it proposes a domain for the rule which is the PW, then it indicated that the method of its application is cyclic. To account for the cases of rule application violation, we proposed a stress-shift rule. The stress-shift rule is not only used to account for the cases of rule application failure, but also to help to understand the way phonological factors such as syllable 
weight, morphological and syntactic factors interact with the application of the stress in NK and prevents its application.

\section{References:}

Ahmed, A. R. (1986). The Phonemic System of Modern Standard Kurdish. Unpublished Ph.D Thesis. University of Michigan.

Al-Mozainy, H. Q., Vroman, R. B. and McCarthy J. T. (1985). Stress shift and metrical structure. Linguistic Inquiry, Vol. 16, No.1, pp. 135-144.

Barker, C. (1989). Extrametricality, the cycle and Turkish word stress. In Phonology at Santa Cruz 1. Santa Cruz: Linguistics Research Centre, pp. 133.

Bedir Khan, Emir Djeladet and Lescot, Roger (1970). Grammaire kurde. Dialecte Kurmanji. Paris: Maisonneuve.

Booij, G. (1996). Cliticisation as prosodic integration: the case of Dutch. The Linguistic Review, 13, pp. 219-242.

Brame, M. K. (1974). The cycle in phonology: stress in Palestinian, Maltese and Spanish. In: Phonological theory: the essential readings. Malden, Massachusetts: Blackwell, pp. 63-83.

Chomsky, N. and Halle, M. (1968). The sound pattern of English. Cambridge, Massachusetts, London: MIT Press.

Cole, J. (1995). The cycle in phonology. In The handbook of phonological theory. Oxford: Blackwell, pp. 70-113.

Dehghan, M. (2012). A short analysis of insertion in Persian. Unpblished MA Thesis. University of Tarbiyat Modares, Tahran, Iran.

Fattah, M. M. (1980). On stress system of Kurdish. Zanco, pp. 177-200.

Gordon, M. (2002). A phonetically-driven account of syllable weight. Language, Volume 78, pp. 51-80 .

Grabe, E. and Warren, P. (1995). Stress shift: do speakers do it or do listeners hear it? In Phonology and Phonetic Evidence: Papers in Laboratory Phonology IV. Cambridge: Cambridge University Press.

Gussenhoven, C. (2005). Procliticized phonological phrases in English: Evidence from Rhythm. Studia Linguistica 59: 174-193.

Hall, T. A. (1999). The phonological word: a review. In U. Kleinhenz and T. A. Hall (eds.), Studies on the phonological word (pp. 1-22). Amestrdam: John Benjamins Publishing Company.

Hall, T. A. (2000). The distribution of trimoraic syllables in German and English as evidence for the phonological word. ZAS Papers in Linguistics, 19, pp. 41-90.

Hannahs, S. J. (1995). The phonological word in French. Linguistics, Volume 33, Issue 6, p. 1125-1144. 
Harris, J. (2011). Deletion. In Marc van Oostendorp, Marc van Oostendorp, Colin J. Ewen, Elizabeth Hume and Keren Rice's Companion to phonology. Oxford: Wiley.

Hasan, A. M. and Rasheed, R. A. (2016). Glide insertion and dialectal variation in Kurdish. European Scientific Journal, Vol. 12, No. 14, pp 289307. Available at http://eujournal.org/index.php/esj/article/view/7451

Hayes, B. (1989a). The prosodic hierarchy in meter. In P. Kiparsky and G. Youmans (eds.), Rhythm and Meter. (pp. 201-260). Orlando: Academic Press. Hayes, B. (1989b). Compensatory lengthening in moraic phonology. Linguistic Inquiry, Vol. 20, No. 2 , pp. 253-306.

Hayes, B. (1995). Metrical stress theory: principles and case studies. Chicago and London: University of Chicago Press.

Hosseini, A. (2011). The prosodization of function words in Persian.In Orientalia Suecana, 61. pp 126-137.

Hosseini, A (2014). The phonology and phonetics of prosodic prominence in Persian, Ph.D dissertation, University of Tokyo. Available at http://roa.rutgers.edu/content/article/files/1314_hosseini_1.pdf

Ito, J. and Mester, A. (2009). The extended prosodic word. In Janet Grijzenhout and Kabak, Bariş (Eds.). Phonological domains: universals and deviations (pp. 135-194). Berlin: Mouton de Gruyter.

Ito, J. and Mester, A. (2012). Recursive prosodic phrasing in Japanese. In Toni Borowsky, Shigeto Kawahara, Takahito Shinya and Mariko Sugahara (Eds.). Prosody matters: essays in honor of Elisabeth Selkirk (pp. 280-303). London: Equinox publishers.

Kabak, B. and Vogel, I. (2001). The phonological word and stress assignment in Turkish. Phonology, No.18, pp. 315-360.

Kahnemuyipour, A. (2003). Syntactic categories and Persian stress. Natural language and linguistic theory, 21 (2). pp. 333-379.

Kaisse, E. M. and Shaw, P. A. (1985). On the Theory of Lexical Phonology. phonology yearbook, Volume 2, pp. 1-30.

Katamba, F. (1989). An introduction to phonology. Essex, England : Longman.

Kiparsky, P. (1982). From cyclic phonology to lexical phonology. In The structure of phonological representations. Foris Publishing, pp. 131-175.

Kiparsky, P. (2000). Opacity and Cyclicity. The Linguistic Review, Volume 17, pp. 351-367.

Kurdish Academy of Language (1992). Retrieved 5, 25, 2009, from http://www.kurdishacademy.org/.

Liberman, M. and Prince, A. (1977). On stress and linguistic rhythm. Linguistic Inquiry, Vol. 8, No. 2, pp. 249-336.

Majid, S. H. (1987). The role of intonation in grammar with reference to English and Kurdish. Unpublished MA Thesis. University of Mosul. 
Mascaro, J. (1976). Catalan phonology and the phonological cycle. PhD thesis. Massachusetts institute of technology.

Mohanan, K. P. (1982). Lexical phonology. MIT Dissertation.

Molczanow, J. (2008). Gliding in Russian. Lingua, Volume 118, pp. 10801108.

Mosa, A. K. (2009). Hêz u awaze le diyaliktî kurdî jûrûda (Stress and Intonation in Northern Kurmanji). Hewler: Kurdish Academy Press.

Nespor, V. and Vogel, I. (2007). Prosodic phonology: with a new foreward. Berlin, New York: Mouton de Gruyter.

Prince, A. (1975). The phonology and morphology of Tiberian Hebrew. Doctoral dissertation. MIT, Cambridge, Massachusetts.

Qadir, S. (1983). The Phonology and Phonetics of Kurdish.Unpublished MA Thesis. University of Essex.

Rubach, J. (1984). Cyclic and lexical phonology: the structure of Polish. Dordrecht: Foris.

Selkirk, E. (1995). The prosodic structure of function words. In: Papers in Optimality Theory. Amherst, MA: GLSA Publications, pp. 439-470.

Shokri, N. (2002). Syllable structure and stress in Bahdinani Kurdish, language typology and universals, Vol 55, No 1. In Geoffrey Haig and Yaron Matras's Kurdish Linguistics. pp. 80-97.

Thackston, W. M. (2006). Kurmanji Kurdish: A Reference Grammar with Selected Readings. [Online].

Uffman, C. (2007). Intrusive [r] and Optimal Epenthetic Consonants. language sciences, 29(45), p. 476.

Yasin, M. S. (2006). ziman u rezmanet kurdi. Dihok: Hawar Press.

Zygis, M. (2010). Typology of consonantal insertions. In M. Weirich and S. Jannedy's Papers from the linguistics laboratory. ZAS Papers in Linguistics , pp. 111-140. 